\title{
Antibiotic Prescribing Pattern at Primary Health Centers in Riyadh City, Saudi Arabia
}

\begin{abstract}
Zainab Albahooth, Primary Healthcare Clinical Pharmacist, Pharmaceutical Care Department, Health Affairs in Riyadh City, Ministry of Heath, Riyadh, SAUDI ARABIA Yousef Ahmed Alomi* iD, BSc. Pharm, MSc. Clin Pharm, BCPS, BCNSP, DiBA, CDE, Critical Care Clinical Pharmacists, TPN Clinical Pharmacist, Freelancer Business Planner, Content Editor and Data Analyst, Riyadh, SAUDI ARABIA.

Samia Zaben Almurshadi, Primary Health Care Clinical Pharmacist, Pharmaceutical Care Department, Health Affairs in Riyadh City, Ministry of Health, Riyadh, SAUDI ARABIA.

Hind Nasser Altamimi,

Primary Health Care Quality Pharmacist, Pharmaceutical Care Department, Health Affairs in Riyadh City, Ministry of Health, Riyadh, SAUDI ARABIA.

Abdulaziz Hussain Alhussain, Pharmacist, Pharmaceutical Care Department, Health Affairs in Riyadh City, Ministry of Health, Riyadh, SAUDI ARABIA.
\end{abstract}

\section{Correspondence:}

Dr. Yousef Ahmed Alomi, BSc. Pharm, MSc. Clin Pharm, BCPS, BCNSP, DiBA, CDE, Critical Care Clinical Pharmacists, TPN Clinical Pharmacist, Freelancer Business Planner, Content Editor and Data Analyst, Riyadh 11392, Riyadh, Saudi Arabia.

Phone no: +966504417712

E-mail: yalomi@gmail.com

Received: 12-11-2020;

Accepted: 05-06-2021.

Copyright: (c) the author(s),publisher and licensee Pharmacology, Toxicology and Biomedical Reports. This is an open-access article distributed under the terms of the Creative Commons Attribution NonCommercial License, which permits unrestricted non-commercial use, distribution, and reproduction in any medium, provided the original work is properly cited.

This is an open access article distributed under the terms of the Creative Commons AttributionNonCommercial-ShareAlike 4.0 License

Access this article online

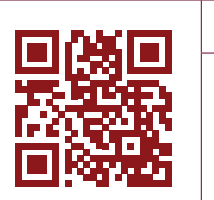

www.ptbreports.org

DOI:

10.5530/PTB.2021.7.17

\begin{abstract}
Objectives: This study aims to identify antibiotic prescribing patterns in Riyadh's Primary health care centers (PHCs). Methods: The study was a one-month cross-sectional medication prescription survey conducted at 25 PHCs in Riyadh. Results: A total of 18031 prescriptions were recorded in all 25 PHCs during the study period. Antibiotics were present in 3,879 (21.51\%) of all prescriptions. The percentage of antibiotics prescribed varied from one primary care center to another; the highest documented percentage was $38.01 \%$. In comparison, the lowest proportion was discovered to be $10.56 \%$ of total antibiotics prescribed, with 3,131 $(80.67 \%)$ being bactericidal and $748(19.3 \%)$ being bacteriostatic. Capsules were the most commonly prescribed antibiotic dosage form 1,240 (32\%), Amoxicillin was the antibiotic most frequently prescribed $1628(42 \%)$, followed by a combination of Amoxicillin/Clavulanate $797(20.5 \%)$. Of the total prescriptions, 2931 (75.6\%) were written with generic names, while 948 $(24.4 \%)$ were written with brand (trade) names. Amoxicillin was the most commonly prescribed antibiotic with a generic name $(52.7 \%)$, while Amoxicillin/Clavulanate was the most usually prescribed antibiotic with the brand name "Augmentin" (69.4\%). The frequency of antibiotics prescribed to patients who did not have a documented indication for Amoxicillin was 270. (6.9\%). Conclusion: Antibiotics were prescribed in one-third of PHC prescriptions. Antimicrobial stewardship programs and training for healthcare professionals are needed at PHCs in Riyadh, Saudi Arabia.
\end{abstract}

Key words: Antibiotic, Prescribing, Pattern, Primary Health Centers, Riyadh City, Saudi Arabia.

\section{INTRODUCTION}

Antibiotics are drugs that are commonly used to treat bacterial infections. The irrational use of antibiotics (IUA) has been a significant concern in most countries' health plans. ${ }^{1}$ Many life-saving interventions, such as tumor chemotherapy and surgery, rely on antibiotic efficacy. ${ }^{2}$ Irrational antibiotic use (IUA) can result in higher treatment costs and severe adverse effects. Antibiotic resistance is common in developing countries, and it is one of the causes of poor treatment outcomes and increased healthcare utilization. ${ }^{3}$ Unnecessary antibiotic prescribing continues to be the most crucial factor in the rise of antibiotic resistance. ${ }^{4,5}$ Unsuitable prescribing leads to treatment failure and compromises patient safety, leading to other issues such as nonadherence. ${ }^{6}$ Recurrent infections, such as urinary tract infections, are becoming more challenging to treat due to global antimicrobial resistance, which has resulted in bacterial resistance to last-line antibiotics. ${ }^{7}$ Primary care physicians write the majority of antibiotic prescriptions. ${ }^{8}$ Inappropriate antibiotic prescribing is linked to several factors. These factors include health care professionals' experience, personal preference, limited knowledge, and patient pressure. ${ }^{910}$ The most effective way to improve medication use in primary health care settings in developing countries is to gather health care professional education, accompanied by peer review, selfmonitoring and feedback, and supervision through programs, therapeutic committees, and antibiotic subcommittees as well as patient education in Saudi Arabia, ${ }^{11}$ where there is legislation or restrictions on their use. Patients are unable to circumvent the healthcare system by purchasing antibiotics from community pharmacies without a prescription.

In Saudi Arabia, healthcare was divided into three sectors. Ministry of Health organized one sector, the second sector is by non- $\mathrm{MOH}$ governmental healthcare organizations, and the third sector is by private institutions. Two third of supported by $\mathrm{MOH}$ and one-third by others. The MOH consisted of more than 280 hospitals and 2250 primary health care centers. ${ }^{12}$ The majority of hospitals and PHCs were located in the Riyadh region, with more than 45 hospitals and 415 primary health care centers. However, Riyadh city had about 120 PHC. The PHC dispenses the medications to the patients through a small pharmacy inside the center. However, after the implementation of Saudi vision $2030 .{ }^{13}$ The new pharmacy practice model is stated through managed care pharmacy by community pharmacy dispensing the PHC prescription one-half of the center and the related hospital called Wasfaty locally. ${ }^{14-17}$ That was created to allow patients to take their medications from the nearest community pharmacy via an electronic platform that connects primary health care centers to these community pharmacies. Was fatty Services aims to improve the quality of care and the safety of all patients and beneficiaries.

Various studies discussed antibiotic prescribing in healthcare services. ${ }^{18-26}$ That has included inpatients, intensive care, ambulatory care, and emergency departments at hospitals. ${ }^{18-27}$ 
However, the consumption or antibiotic prescribing at the primary health care center is rarely investigated locally. ${ }^{27-32}$ Therefore, this study aimed to present a complete matching picture of the prescribing pattern and accurately reflect the prescribing rate at PHCs.

\section{METHODS}

The study was a retrospective analysis of antibiotic prescribing patterns at PHCs in Riyadh City, Saudi Arabia. Around 120 primary healthcare centers serve the city of Riyadh, spread across five health sectors. We used a random sample to select 25 PHCs for this study. These centers were typical of those throughout the city, providing services to a large population representing Riyadh City. Primary health care services include preventative and curative care but do not cover all specialties. PHCs primarily offer specialty programs in vaccination, child health care, chronic disease management, pregnancy care, dental care, health education, and referral. The intended audience consisted of all patients who visited primary care clinics. Data from 25 PHCs were analyzed retrospectively for one month, in December 2018. Antibiotic prescription records from all outpatient visits were used in the study. Antibiotics Prescriptions written by physicians working in these primary care health centers were recorded and analyzed to determine prescribing patterns within the PHCs. The Pharmacists used the antibiotic form to record information about all prescriptions for one month. The format consisted of the patient's age, diagnosis, gender, antibiotic name, antibiotic class, dosage form, route of administration, treatment duration, number of antibiotics in one prescription, antibiotic is given as treatment or prophylaxis, number of medications in one prescription, and so on. Except for weekends, data was collected every day. Permission to conduct the research was obtained from the general administration for analyses and studies at the Ministry of Health (1440-1033702).

A letter of approval was sent to the health sector. The Statistical Package for the Social Sciences (SPSS) version 24 software analyzed the data. Frequencies and percentages were calculated using descriptive statistics. The Chi-Square test was used to compare means among categorical variables, while the independent $t$-test and ANOVA were used to compare means among numerical variables. The WHO/INRUD core prescribing indicators (The standard World Health Organization/International Network for Rational Use of Drugs prescribing indicators) were used to determine physician prescribing practices) chosen based on the previous studies. ${ }^{33-35}$ The proportion of antibiotic-containing prescriptions was calculated by dividing the number of antibiotic-containing prescriptions by the total number of prescriptions from all study centers during the study period. Percentage of antibiotic prescription encounters (standard value $20.0 \%-26.8 \%$ ), Percentage of drugs prescribed by generic name (standard value 100\%), and Percentage of drugs prescribed from the essential drug list/drug formulary (standard value 100\%).

\section{RESULTS}

During the study period, all 25 PHCs recorded a total of 18031 prescriptions. Of those total prescriptions, there were 3,879 prescriptions (21.51\%) that contained antibiotics. Table 1 shows a description of patients who have prescriptions for antibiotics. Male patients made up 1,709 (44.1\%), while females made up 2,170 (55.9\%). The patients' mean age (standard deviation) was 29.1 years (20.0\%). 3538 (91.2\%) prescriptions were for Saudi nationals, while 341 (8.9\%) were for nonSaudi nationals. 265 (6.8\%) of the total patients had a history of antibiotic allergy, and $50(18.8 \%)$ of them were prescribed an alternative antibiotic, while only $1(2 \%)$ were not. Three $(5.9 \%)$ of the 50 patients were given Ciprofloxacin, eight (16\%) were given Clarithromycin, and 39 (78\%) were given Erythromycin.

\begin{tabular}{|l|l|c|c|}
\hline $\begin{array}{l}\text { Table 1: Distribution of antibiotic prescription based on patients' } \\
\text { characteristics ( } \boldsymbol{n}=\mathbf{3 8 7 9 )}\end{array}$ \\
\hline \multicolumn{3}{|c|}{ Variables } \\
\hline \multicolumn{3}{|c|}{ Age Mean (SD): 29.1 (20.0) } \\
\hline & Male & 1709 & 44.1 \\
\hline Gender & Female & 2170 & 55.9 \\
\hline & Saudi & 3538 & 91.2 \\
\hline Nationality & Non-Saudi & 341 & 8.9 \\
\hline & Yes & 256 & 6.8 \\
\hline History of drug allergy & No & 3623 & 93.4 \\
\hline & & &
\end{tabular}

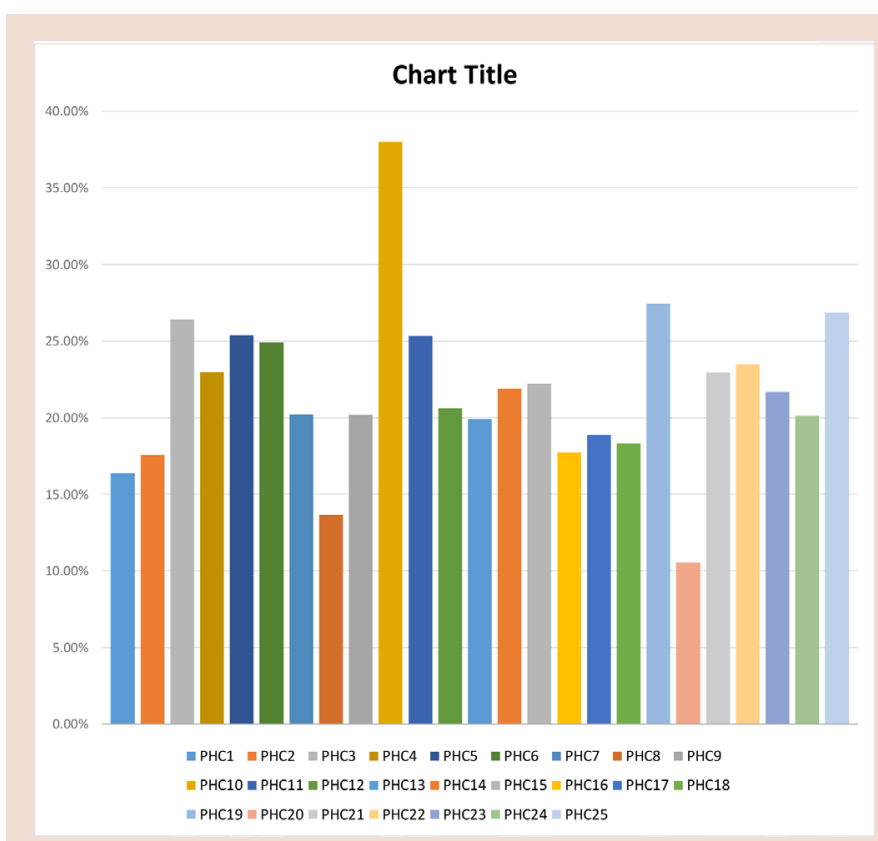

Figure 1: The percentage of prescriptions containing antibiotics at PHCs.

The percentage of antibiotic prescriptions varies from one primary health center to the next; Figure 1 depicts the percentage of antibiotic prescriptions in each primary health center. The highest recorded percentage was $38.01 \%$, followed by $27.43 \%$ and $26.84 \%$, and the lowest was $10.56 \%$, followed by $13.46 \%$. The proportion of prescriptions containing antibiotics in the other PHCs ranged between 15 and 25\%. Table 2 shows the frequency with which antibiotics are prescribed at PHCs. 39\% of the 3,879 antibiotic prescriptions examined contained only antibiotics, while 3570 (92\%) contained antibiotics combined with other medications. The average (standard deviation) of antibiotic prescriptions per day was 44.2. (28.06). The frequency of prescriptions containing a single antibiotic was $3,510(90.5 \%)$, two antibiotics $363(9.4 \%)$, and three antibiotics $66 \%$. (0.2\%). Of the total antibiotics prescribed, 3,131 (80.67\%) were bactericidal, while 748 (19.3\%) were bacteriostatic. Capsules were the most commonly prescribed antibiotic dosage form $(1,240(32 \%))$, followed by syrups $(1,001(25.8 \%)$ and tablets (964). (24.9\%). The most common route of antibiotic administration was oral 3274 (84.4 \%), followed by ear, nose, and throat (ENT) 324 (8.4\%), and finally topical 281 (8.4\%) (7.2). of the total prescriptions, 3,831 (98.8\%) were for disease treatment, while $48(1.2 \%)$ were for prophylaxis. 


\begin{tabular}{|c|l|c|c|}
\hline \multicolumn{5}{|c|}{ Table 2: Frequency of antibiotics prescribed $(\boldsymbol{n}=\mathbf{3 8 7 9})$. } \\
\hline No. & Antibiotic & Frequency & Percent \\
\hline 1 & Amoxicillin & 1628 & 42.0 \\
\hline 2 & Amoxicillin/Clavulanate & 797 & 20.5 \\
\hline 3 & Azithromycin & 378 & 9.7 \\
\hline 4 & Trimethoprim/Sulfamethoxazole & 141 & 3.6 \\
\hline 5 & Chloramphenicol & 39 & 1.0 \\
\hline 6 & Ciprofloxacin & 61 & 1.6 \\
\hline 7 & Clarithromycin & 16 & 0.4 \\
\hline 8 & Doxycycline & 73 & 1.9 \\
\hline 9 & Erythromycin & 46 & 1.2 \\
\hline 10 & Flamazine & 37 & 1.0 \\
\hline 11 & Fucidin & 234 & 6.0 \\
\hline 12 & Gentamicin & 246 & 6.3 \\
\hline 13 & Metronidazole & 78 & 2.0 \\
\hline 14 & Tetracycline & 105 & 2.7 \\
\hline
\end{tabular}

\begin{tabular}{|c|c|c|c|c|}
\hline \multicolumn{5}{|c|}{$\begin{array}{l}\text { Table 3: WHO/INRUD prescription indicators at the primary health care } \\
\text { center. }\end{array}$} \\
\hline $\begin{array}{l}\text { Prescribing } \\
\text { indicator }\end{array}$ & $\begin{array}{l}\text { No of } \\
\text { antibiotics }\end{array}$ & $\begin{array}{l}\text { Total } \\
\text { number of } \\
\text { antibiotics }\end{array}$ & Percent & $\begin{array}{l}\text { Standard } \\
\text { Percent }\end{array}$ \\
\hline $\begin{array}{l}\text { Antibiotics written by } \\
\text { generic names }\end{array}$ & 2931 & 3879 & $75.6 \%$ & $100 \%$ \\
\hline \multirow[t]{2}{*}{ Formulary antibiotics } & 3789 & 3789 & $100 \%$ & $100 \%$ \\
\hline & $\begin{array}{l}\text { No of } \\
\text { antibiotics }\end{array}$ & $\begin{array}{l}\text { Total } \\
\text { number of } \\
\text { prescriptions }\end{array}$ & Percent & $\begin{array}{l}\text { Standard } \\
\text { Percent }\end{array}$ \\
\hline $\begin{array}{l}\text { Number of prescribed } \\
\text { antibiotics }\end{array}$ & 3879 & 18031 & $21.51 \%$ & $20.0-26.5 \%$ \\
\hline
\end{tabular}

Antibiotics were most commonly prescribed for upper respiratory tract infection (URTI) 855 (22.0\%), tonsillitis 548 (14\%), and otitis 270 (7\%). Amoxicillin was the most commonly prescribed antibiotic 1628(42\%), followed by a combination of Amoxicillin/Clavulanate (Augmentin) 797(20.5\%) and Azithromycin 378. (9.7\%). Clarithromycin 16 (0.4\%) was the antibiotic that was prescribed the least. The frequency of antibiotics prescribed is shown in Table 2. A total of 2931 prescriptions (75.6\%) were written with generic names, while 948 (24.4\%) were written with brand (trade) names. Amoxicillin was the most commonly prescribed antibiotic with a generic term (52.7 \%), while Amoxicillin/Clavulanate was the most commonly prescribed antibiotic with the brand name "Augmentin" (69.4\%). Amoxicillin was prescribed to 270 patients (6.9\%), Amoxicillin/Clavulanate to 124 (3.7\%), and Azithromycin to 26 patients $(6.9 \%)(0.7 \%)$. The antibiotics prescribed were all from the Ministry of Health's Formulary. The World Health Organization/ International Network of Rational Use of Drugs prescription (WHO/ INRUD) indicators of the prescribed antibiotics are shown in Table 3. The most prescribed antibiotics were Penicillins class 2425 (64\%), followed by macrolides $438(11.5 \%)$ and aminoglycosides 246 (6.5\%), as explored in Figure 2.

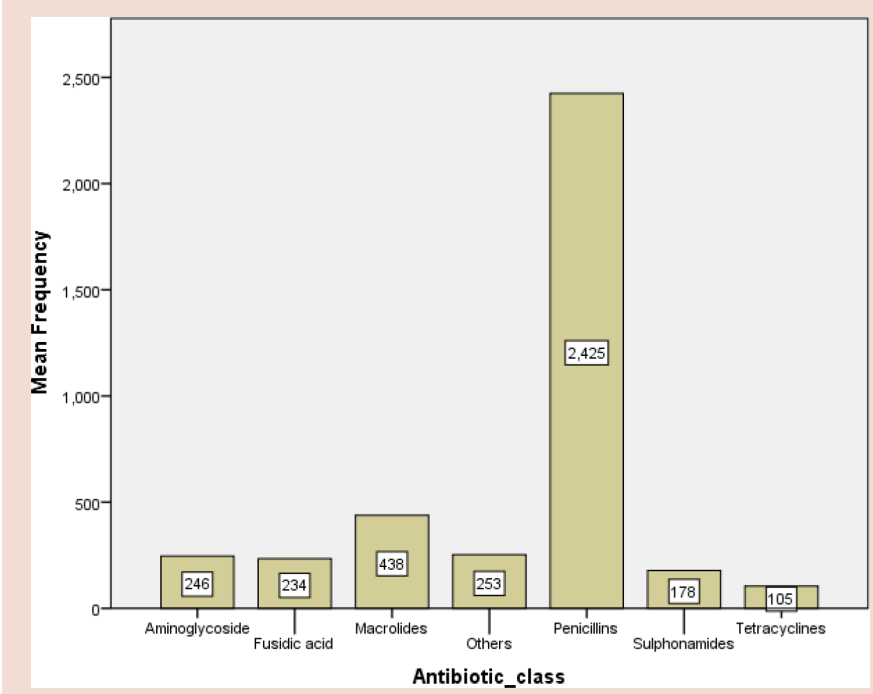

Figure 2: Most commonly prescribed antibiotic classes.

\section{DISCUSSION}

Several studies show that irrational antibiotic use is a worldwide phenomenon. The problem is more visible in developing countries with no comprehensive and useful policies on antibiotic prescribing or where such a system is inadequate. For example, Saudi Arabia has expressed a strong desire to improve its healthcare system significantly. The emergence of drug resistance is a significant source of concern because it raises healthcare costs, lengthens hospital stays, and increases the likelihood of adverse drug reactions (ADR) and drug interactions. ${ }^{36}$ Various pharmacy practice programs have been established at the ministry of health hospitals. That has included medication safety, anticoagulation program, and Antimicrobial stewardship programs. ${ }^{37-39}$ The first step of the antibiotics program is to identify the antibiotics consumption at healthcare organizations. Various studies were conducted at different hospital sections. The current research shows antibiotic prescribing at the primary health care center only. It was through retrospective analysis of 25 primary health care centers in Riyadh city. As part of Antimicrobial stewardship programs. Antibiotic prescribing patterns in PHCs should be named appropriately to prevent or minimize antimicrobial resistance. The study published comprehensive data on antibiotic prescription patterns in PHCs in Riyadh, Saudi Arabia. It was a critical issue because understanding the practice of prescribing antibiotics will lead to establishing policies that govern antibiotic prescribing and dispensing, reducing the problems associated with irrational prescribing, dispensing, and consumption of antibiotics.

Antibiotic prescribing and use in outpatient settings decreased by $5 \%$ nationally between 2011 and $2014 .{ }^{40}$ A study in Turkey found that the proportion of antibiotic prescriptions in PHC settings was similar to our findings. ${ }^{30}$ According to another study conducted in Botswana's primary healthcare facilities, the overall antibiotic prescribing rate was high. That might be related to different types of patients or antibiotic policy or antimicrobial stewardship programs not implemented. ${ }^{31}$

Most antibiotic prescriptions contained a single antibiotic in the current study, while less than one percent contained three antibiotics, which was a good indicator at primary healthcare centers. Thus, practitioners should keep the average number of antibiotics as low as possible to avoid the emergence of resistant organisms. Nonetheless, depending on the severity of the infection, particularly in hospitalized patients, physicians may prescribe more than one antibiotic to alleviate the severity of illness. ${ }^{41}$ 
The percentages of antibiotic prescriptions vary among the PHCs included in the study, with the highest documented rate being $10-40 \%$. These differences could be attributed to differences in attitudes toward antibiotic prescribing and the level of education among PHC prescribers. Approximately three-quarters percent of the drugs in the prescriptions were written in generic names, which exceeds previous studies' findings. ${ }^{22,28}$ That's related to the entire regulation from $\mathrm{MOH}$ to write the medications in generic name. However, one-quarter percent report in trade names. That's related to the clinician's preference for antibiotic brand names, which could be due to pharmaceutical companies' promotional, marketing, and advertising activities that spend more on advertising and marketing than on research and development. ${ }^{42}$ Thus, the reported percentage of prescriptions written in generic names is lower than the standard value, indicating that additional efforts should be made to highlight the problem of writing prescriptions by brand names, which has been confirmed to be an illegal practice. ${ }^{43}$

The percentage of drugs prescribed from the drug formulary was satisfactory $(100 \%)$, the same as the standard value, which had better results than reported in the Nepal study. ${ }^{29}$ The advanced healthcare system and strict rules, regulations, and monitoring in a developed country like Saudi Arabia may reflect this difference with a developing country like Nepal. ${ }^{29}$

The most prescribed antibiotics were Penicillin, macrolides, and aminoglycosides, similar to previous local studies. ${ }^{27}$ On the contrary, tetracycline's were the most minor prescribed class. These findings differed from a Jazan study, Saudi Arabia. The cephalosporins were the most frequently prescribed antibiotics with a higher percentage than the current study. Besides, it was different sequences of antibiotics; aminoglycosides and penicillins. ${ }^{23}$ Again, the Cephalosporins and penicillins accounted for most total antibiotics prescribed in Malawian ${ }^{24}$ and Albania. ${ }^{25}$ Another study in Yemen and Cameron or locally showed that Amoxicillin was the most commonly prescribed antibiotic in the same context. That's consistent with the findings of current studies..$^{22,32,27}$ Amoxicillin-Clavulanic acid was the second most widely prescribed antibiotic, similar to Indian and local studies that found AmoxicillinClavulanic acid to be the most frequently prescribed antibiotic. ${ }^{26,27}$

Various factors might affect the variations in the previous studies' findings. For instants, differences in bacterial susceptibility, disease epidemiology, local prescribing guidelines, strategies for infectious diseases, and treatment modalities. Besides, the country and organizational therapy policies, healthcare system, healthcare delivery facilities, individual healthcare providers, and patient characteristics in different geographical areas. All possible explanations for such disparities results.

In 2012, the General Administration of Pharmaceutical Care in Saudi Arabia began implementing a pharmacy strategic plan in hospitals, including an antimicrobial stewardship program at PHCs. The conscious implantations of the program to cover all PHCs in optimal level required to achieve in the Kingdom of Saudi Arabia. ${ }^{39}$

\section{CONCLUSION}

Antimicrobial resistance is caused by unnecessary use, insufficient duration of therapy, inappropriate doses, and irrational fixed-dose drug combinations. As a result, this study was conducted to investigate the pattern of antibiotic prescribing in PHCs. This study provided a good picture of the pattern of antibiotic prescribing in PHCs in KSA, which provided valuable data that could aid in the development of interventions aimed at increasing antibiotic use. However, because the study was conducted in only the capital city of Riyadh and for a short period, it cannot be generalized to the entire country. Furthermore, it implies the long-term need for similar studies in other parts of the country. Nonetheless, this study has far-reaching implications for policy and practice. The findings indicate an urgent need to train prescribers and educate the public to prevent inappropriate antibiotic prescribing and use.

\section{ACKNOWLEDGEMENT}

None.

\section{CONFLICT OF INTEREST}

The authors declare that there is no conflict of interest.

\section{Funding}

None

\section{Ethical Approval}

Permission to conduct the research was obtained from the general administration for analyses and studies at the Ministry of Health.

\section{ABBREVIATIONS}

IUA: Irrational use of antibiotics; PHCs: Primary healthcare center; MOH: Ministry of Health, KSA: Kingdom of Saudi Arabia; USA: The United States of America; WHO/INRUD: World Health Organization/ International Network of Rational Use of Drugs prescription; SPSS: Statistical Package for the Social Sciences.

\section{ORCID ID}

Yousef Ahmed Alomi (D) https://orcid.org/0000-0003-1381-628X

\section{REFERENCES}

1. Dijk KH, L. Van. The world medicines situation 2011: Rational use of medicines. Vol. 2. World Health Organization; 2011.

2. Teillant A, Gandra S, Barter D, Morgan DJ, Laxminarayan R. Potential burden of antibiotic resistance on surgery and cancer chemotherapy antibiotic prophylaxis in the USA: A literature review and modelling study. Lancet Infect Dis. 2015;15(12):1429-37. doi: 10.1016/S1473-3099(15)00270-4

3. Cosgrove SE, Carmeli Y. The impact of antimicrobial resistance on health and economic outcomes. Clin Infect Dis. 2003;36(11):1433-7. doi: 10.1086/375081, PMID 12766839.

4. Sigvard Mov L, Lundborg CSL. Karlsson4, ANNA-KARINaCARS2 nd $O$. Antibiotic Prescription Rates Vary Markedly between 13 European Countries. Scand J Infect. 2002;34:366-71. Available from: papers2://publication/ doi/10.1080/00365540110080034.

5. Besser RE. Antimicrobial prescribing in the United States: good news, bad news [internet]. Ann Intern Med. 2003;138(7):605-6. doi: 10.7326/0003-4819138-7-200304010-00020, PMID 12667034

6. Reddy SC, Jacob JT, Varkey JB, Gaynes RP. Antibiotic use in US hospitals: Quantification, quality measures and stewardship [internet]. Expert Rev Anti Infect Ther. 2015;13(7):843-54. doi: 10.1586/14787210.2015.1040766, PMID 25925531.

7. Zowawi HM, Harris PNA, Roberts MJ, Tambyah PA, Schembri MA, Pezzani MD, et al. The emerging threat of multidrug-resistant Gram-negative bacteria in urology. Nat Rev Urol. 2015;12(10):570-84. doi: 10.1038/nrurol.2015.199, PMID 26334085.

8. Goossens H, Ferech M, Vander Stichele R, Elseviers M, ESAC Project Group Outpatient antibiotic use in Europe and association with resistance: A crossnational database study. Lancet. 2005 Feb 12;365(9459):579-87. doi: 10.1016/ S0140-6736(05)17907-0, PMID 15708101.

9. Farid S, Akter U, Fauzi M, Rani A, Rahman JA. Antimicrobial use and factors influencing prescribing in medical wards of a tertiary care hospital in Malaysia. Int J Sci. 2012;1.

10. Teng $\mathrm{CL}$, Tong SF, Khoo EM, Lee $\mathrm{V}$, Zailinawati $\mathrm{AH}$, Mimi $\mathrm{O}$, et al. Antibiotics for URTI and UTI -- prescribing in Malaysian primary care settings. Aust Fam Physician. 2011;40(5):325-9. PMID 21597554.

11. Holloway K. Promoting the rational use of antibiotics. Vol. 15(1). p. 122-30; 2011 Reg Heal Forum [internet]. Available from: http://www.searo.who.int/LinkFiles/ Regional_Health_Forum_RHF_Vol_15_No_1.pdf [cited 22/11/2021].

12. Saudi Ministry of Health. Statistical [yearbook] [internet]. Ministry of Health; 2020 [cited Nov 10 2021]. Available from: https://www.moh.gov.sa/en/Ministry/ Statistics/book/Pages/default.aspx.

13. Government of Saudi Arabia. Saudi Arabia vision. Vol. 2030 [internet]; 2016 Available from: https://vision2030.gov.sa/sites/default/files/report/Saudi_Vision2030 EN_2017.pdf [cited 22/11/2021]. 
14. Commun Med. 2017;3(3).

15. Alomi YA, Alghamdi SJ, Alattyh RA, Elshenawy RA. The evaluation of pharmacy strategic plan in past. Commun Med. 2013-2016 and Forecasting of New Vision 2030 at Ministry of Health in Saudi Arabia. J Pharm Pract;2018(Jun 10);4(2):93-101.

16. Alomi YA, Alghamdi SJ, Alattyh RA. Saudi managed care pharmacy (SMCP): New initiative system of $\mathrm{MOH}$ prescriptions dispensed through community pharmacies. J Pharm Pract. Commun Med. 2017;3(3).

17. Aloola NAl, Aljudaib S, Behery F, Alwhaibi M, Alhawassi T. Perception of Saud community towards the transition of pharmaceutical care services from the Ministry of Health Primary Healthcare Centers to the community pharmacies. Res Sq. 2020;12:1-20.

18. Alomi YA, Almasoudi AH, Alghamdi GA, Abboud NA. Antimicrobial drug consumption in emergency services at North West (Tabuk). Saudi Arabia: Region Hospitals. Pharmacol Toxicol Biomed Reports; 2019;5(3). p. 108-12.

19. Alomi YA, Almasoudi AH, Alghamdi GA, Ali Asiri S. Analysis of antimicrobial medication consumption in Intensive Care Unit. Saudi Arabia: North West (Tabuk) Region Hospitals. Pharmacol Toxicol Biomed Reports; 2019;5(3). p. 119-23.

20. Almasoudi $\mathrm{AH}$, AlomiYA, Alghamdi GA, Alshahrani RS. Analysis of antimicrobia medications consumption in inpatient units at North West (Tabuk). Saudi Arabia: Region Hospitals. Pharmacol Toxicol Biomed Reports; 2019;5(3):130-4.

21. Almasoudi $\mathrm{AH}$, Alomi $Y$ A, Alghamdi GA. Antimicrobial drug consumption in ambulatory care settings, Tabuk region, Saudi Arabia. PTB Reports. 2019;5(3):97-101. doi: 10.5530/PTB.2019.5.18

22. Alshakka M, Said K, Babakri M, Ansari M, Aldhubhani A, Azmi Hassali M, et al. A study on antibiotics prescribing pattern at outpatient department in four hospitals in aden-Yemen. J Pharm Pract. Commun Med. 2016;2(3):88-93.

23. Alakhali KM, Mohammad AAS. Prescribing pattern of antibiotics in pediatric patients in the Jazan region, Kingdom of Saudi Arabia. RGUHS J Pharm Sci. 2014:4(3):120-4. doi: 10.5530/rjps.2014.3.6.

24. Kasenda S, Mategula D. Geoffrey Elihu Manda TKC. Bacteriology and antibiotic prescription in a Malawian Tertiary Hospital Burns Unit. Burn AMR. 2018 (Sep):160-4

25. Mihani J, Këlliçi S. Patterns of antibiotic prescription in children: Tirana, Albania Region. Open Access Maced J Med Sci. 2018;6(4):719-22. doi: 10.3889/ oamjms.2018.150, PMID 29731947.

26. Gupta CN, Chatterjee K. Prescription pattern of antibiotics in respiratory disorders in a tertiary care teaching hospital in Eastern part of India. Int J Res Med Sci. 2017;5(4):1430-3. doi: 10.18203/2320-6012.ijrms20171240.

27. Mollahaliloglu S, Alkan A, Donertas B, Ozgulcu S, Akici A. Assessment of antibiotic prescribing at different hospitals and primary health care facilities. Saudi Pharm J. 2013;21(3):281-91. doi: 10.1016/j.jsps.2012.10.004, PMID 23960845

28. Bashrahil KA. Indicators of rational drug use and health services in Hadramout, Yemen. East Mediterr Health J. 2010;16(2):151-5. doi: 10.26719/2010.16.2.151, PMID 20799566.
29. Dahal P, Bhattarai B, Adhikari D, Shrestha R, Baral S, Shrestha N. Drug use pattern in Primary health care facilities of Kaski District, Western Nepal. Sunsari Tech Coll J. 2013;1(1):1-8. doi: 10.3126/stcj.v1i1.8652.

30. Acimis NM, Yazici AC, Gocmen L, Mas R. The prevalence of prescribing antibiotics by primary health care physicians in Turkey: A multi-centered survey. Pak J Med Sci. 2009;25(5):706-11.

31. Mashalla $Y$, Setlhare $V$, Massele A, Sepako E, Tiroyakgosi C, Kgatlwane J, et al. Assessment of prescribing practices at the primary healthcare facilities in Botswana with an emphasis on antibiotics: findings and implications. Int J Clin Pract. 2017;71(12):1-14. doi: 10.1111/ijcp.13042.

32. Chem ED, Anong DN, Akoachere JKT. Prescribing patterns and associated factors of antibiotic prescription in primary health care facilities of Kumbo East and Kumbo West Health Districts, North West Cameroon. PLOS ONE. 2018;13(3):1-18. doi: 10.1371/journal.pone.0193353.

33. EI MAA. WHO/INRUD drug prescribing indicators at primary health care centers in Eastern Province, Saudi Arabia. East Mediterr Heal J. 2010;18(11):1091-6.

34. Akl OA, El Mahalli AA, Elkahky AA, Salem AM. WHO/INRUD drug use indicators at primary healthcare centers in Alexandria, Egypt. J Taibah Univ Med Sci. 2014;9(1):54-64. doi: 10.1016/j.jtumed.2013.06.002.

35. Atif M, Sarwar MR, Azeem M, Umer D, Rauf A, Rasool A, et al. Assessment of WHO/INRUD core drug use indicators in two tertiary care hospitals of Bahawalpur, Punjab, Pakistan. J Pharm Policy Pract. 2016;9(1):27. doi: 10.1186/ s40545-016-0076-4, PMID 27688887.

36. Sheth KV, Patel TK, Malek SS, Tripathi CB. Antibiotic sensitivity pattern of bacterial isolates from the intensive care unit of a tertiary care hospital in India. Trop J Pharm Res. 2012;11(6):991-9. doi: 10.4314/tjpr.v11i6.17.

37. Alomi YA. National medication safety program at Ministry of Health in Saudi Arabia. J Pharmacovigil. 2015;03(5):e145. doi: 10.4172/2329-6887.1000e145.

38. Alomi YA. National pharmacy anticoagulation program at Ministry of Health in Saudi Arabia. BAOJ PharmSci. 2017;3(3):3-7.

39. Alomi YA. National antimicrobial stewardship Program in Saudi Arabia; initiative and the future. OAJS. 2017;4(5):1-7. doi: 10.19080/OAJS.2017.04.555646.

40. Center of Diseases Control. Antibiotic use in the United States, 2017: progress and opportunities [internet]. United States Department of Health and Human Services, Centers for Disease Control and Prevention (US); 2017. Available from: https://www.cdc.gov/antibiotic-use/stewardship-report/pdf/stewardship-report. pdf [cited 22/11/2021].

41. TRIPATHI K. Antimicrobial drugs: general considerations. Essentials Med Pharmacol. 2013:688-704.

42. Lexchin J. Pharmaceutical company spending on research and development and promotion in Canada, 2013-2016: A cohort analysis. J Pharm Policy Pract. 2018;11(1):5. doi: 10.1186/s40545-018-0132-3, PMID 29564139.

43. Flegel K. The adverse effects of brand-name drug prescribing. CMAJ. 2012;184(5):616. doi: 10.1503/cmaj.112160, PMID 22371517 